\title{
A Longitudinal Study of Motivation in Foreign and Second Language Learning Context
}

\author{
Eser Ordem ${ }^{1}$ \\ ${ }^{1}$ Translation and Interpreting, Adana Science and Technology University, Adana, Turkey \\ Correspondence: Eser Ordem, Translation and Interpreting, Adana Science and Technology University, Adana, \\ Turkey. E-mail: eordem@adanabtu.edu.tr
}

Received: February 22, 2017

Accepted: March 25, 2017 Online Published: April 10, 2017

doi:10.5539/jel.v6n2p334

URL: http://dx.doi.org/10.5539/jel.v6n2p334

\begin{abstract}
Although motivation has been one of the most commonly studied subjects in second and foreign language learning in recent decades, it still remains an enigma for learners and teachers. This longitudinal study aimed to follow a student $(\mathrm{N}=1)$ studying German in both second and foreign language environment for three years. The study was descriptive, idiographic and phenomenographic in nature with the support of interpretive phenomenological analysis. Interview and diary methods were used to collect data about the nature of motivation of the participant. The study contained seven dimensions of motivation to interpret the data. The results showed that the participant was adversely affected by lack of linguistic self-confidence and the problem of milieu and that an individual's own efforts to reach high motivation might be insufficient without taking external factors into consideration. It was also found that a long observation of motivation has a dynamic, chaotic and complex nature.
\end{abstract}

Keywords: L2 motivation, second/foreign language learning, complexity theory

\section{Introduction}

Motivation has been one of the core issues in all human and social sciences for decades since heightened and sustained motivation may not be encountered particularly in educational contexts such as foreign language classrooms. Therefore, research into motivation in foreign and second language learning has also gained momentum in recent years. Boo, Dörnyei and Ryan (2015) also note that L2 motivation studies have been on the increase, although it is one of the most investigated areas in second language acquisition field. There have been major assumptions regarding the nature of motivation. Gardner (1985) evaluated motivation from a socio-educational perspective mainly classifying motivation types as instrumental and integrative. Bandura (1997) studied motivation under the general term of self-efficacy within social cognitive framework. Deci and Ryan (1985) noted that self-determination including the basic elements of competence, relatedness and autonomy is important in providing motivation. Weiner (2010) focuses on the significance of attribution and attributional perceptions to analyze and predict motivation. The willingness to communicate is another term to understand the nature of motivation and pyramidically encompasses various constructs (MacIntyre, Dörnyei, Clement, \& Noels, 1998). Dörnyei (2009) views motivation as a self-system composed of possible selves affecting learners' motivational level. However, in recent years motivation has been conceptualized as a dynamic, chaotic and complex system (Dörnyei, MacIntyre, \& Henry, 2014). Complexity theory has enabled motivation systems to be dynamically appraised and evaluated since this theory rules out any kind of linear, causal and mechanical explanation but instead stresses the importance of adaptation or complex adaptation system (Larsen-Freeman, 1997; Larsen-Freeman, 2012; Larsen-Freeman \& Cameron, 2008).

This study aims to analyze the dynamics of motivation experienced by a Turkish participant by taking into account seven motivational components originally developed by Dörnyei and Csizér (2002). These dimensions are integrativeness, instrumentality, vitality of the L2 community, attitudes toward the L2 speakers/community and cultural interest, linguistic self-confidence and milieu. Integrativeness refers to one's favorable perspective and inclination towards another culture (Gardner, 2001). Instrumentality, in its general use, denotes pragmatic purposes (Dörnyei, 2002). As for the dimension of vitality of the L2 community, it is defined as perceived importance and wealth of the target language in question (Dörnyei \& Csizér, 2002). Attitudes toward the L2 speakers/community depict an attitude towards contact with members of L2 community. Cultural interest is 
mostly related to indirect interest in L2 community. Linguistic self-confidence refers to one's potential and ability to establish social contact with L2 speakers. Lastly, milieu describes the importance of social influence deriving from the immediate environment. These dimensions were analyzed within the framework of complex dynamic systems theory that approaches motivation issue taking adaptation and non-linearity into consideration.

\subsection{Present Study}

Although motivation studies in SLA have been examined from different perspectives and theories on account of its dynamic and distinct nature, almost each study on motivation often sparks interest since motivation is a complex and chaotic system. This issue is still not clear how second language learners with low motivation can sustain their motivation at a high level. This idiographic study was designed as qualitative longitudinal conducting a phenomenographic analysis. This longitudinal study examined the motivational processes and experiences of a Turkish participant trying to learn German both in the home country, Turkey and the target country, Germany. The study took three years and was composed of diary and interview instruments.

\subsection{Research Questions}

This study is idiographic and phenomenographic in nature. Marton (1981) states that phenomenography aims to analyze the variation of an individual's views and conceptions of a certain phenomenon in a certain context. In addition, phenomenography studies are designed to find out what is in the focus of individuals and how these individuals intentionally create meaning in an interactive context of a certain phenomenon (Marton, 1997). Categories obtained from results are generally interpreted hierarchically within a theoretical framework. Any research aiming to analyze an individual's conceptualization, interpretation and understanding of certain phenomena in a certain environment is in nature qualitative (Bowden, Dall'Alba, Martin, Laurillard, Marton, Masters, \& Walsh, 1992). In accordance with this research method, the main aim of this present study is to uncover the dynamic nature of motivation of a Turkish participant learning German as a second and foreign language by collecting data through a diary and semi-structured interview questions. In the light of this purpose, answers to the following questions were sought:

Research Question 1: What motivational processes did the participant undergo within three years?

Research Question 2: What dimension(s) affect the participant's motivation positively and adversely?

\section{Methodology}

\subsection{Research Design}

This study was designed as qualitative using diary and interview, which are two methods of data collection in qualitative research. A diary study, mainly composed of two types, time-based and event-based, is a method containing elaborate accounts of a phenomenon in a participant's environment with intensive, dynamic and reflective self-reports. In this study, the participant was asked to keep both time-based and event based diary. Semi-structured interviews are also qualitative in nature and provide authentic interaction, thematic, narrative or biographical information and enriched contextual clues about the phenomenon studied (Mason, 2002; Wengraf, 2001).

\subsection{Data Collection}

A diary method and semi-structured interviews were used to collect data. Therefore, a two-stage process was followed to elicit data from the participant. The study was commenced in November, 2013. In stage one, the researcher asked the participant to keep a diary based on time-based and event-based. In stage two, the researcher met the participant almost once a month to make semi-structured interviews about her motivation. The number of the interviews was thirty two in total. Each interview lasted between fifteen and thirty minutes. The purpose of these frequent interviews was to identify the complex and dynamic nature of a second language learner's motivation. After the verbatim transcriptions were obtained, each sentence containing motivation was analyzed.

\subsection{Participant}

The study involved a Turkish participant (a pseudonym, Nil) learning German as a second and foreign language to study architecture in Germany. She could not speak another third language at all. She had no prior knowledge of German and started to learn German in her home town, Turkey, by attending two private courses teaching a six hour class a week at the age of 30 for three months. Before leaving for Germany, the participant's German level was A1.1. After the arrival in Germany, the participant took 20 hours on weekdays for a year ending B2.2. level. After a year, the participant came back to Turkey and continued to learn German for two years. Although 
her aim was to pass the Test DAF exam (Test Deutsch als Fremdsprache/Test of German as a foreign language) to study architecture at the university, her ideal was to have an advanced German.

\subsection{Procedure}

Before the study was started, the researcher who met the participant to inform that this study would involve motivation and could take long time presented information about the study techniques, the diary and semi-structured interviews. In addition, seven motivational components were explained to her in detail. The researcher gave the participant a notebook containing the purpose of the study, some guiding questions and instructions. In order for the participant not to quit the study and to motivate her about the importance of the study, the researcher made regular semi-structured interviews to elaborate on and extend the diary notes written by her. The interviews were made on the phone and face to face depending on the researcher's visits to the target country.

\subsection{Data Analysis}

The participant kept a 150 day journal containing information about motivation and was interviewed 30 times within three years. The on-the-phone interviews were also transcribed. Each sentence about the motivation was analyzed and coded by seven motivational dimensions developed by Dörnyei and Csizér (2002).

\section{Results}

This study aimed to analyze the dynamics of motivation experienced by taking seven motivational components into consideration. The overall results show that the participant had a dynamic and chaotic nature of motivation and that linguistic self-confidence and social milieu had a more profound and adverse effect on her motivation, whereas she had high motivation in the components of integrativeness, instrumentality, vitality of the L2 community, attitudes and cultural interest.

\subsection{Components of Motivation}

\subsubsection{Integrativeness}

The participant stated that she, initially, had a neutral perspective towards German culture but developed a more integrative inclination after living in Germany for a year. Her return to home country caused her to feel isolated from the target country and not to study the target language for almost 11 months since she had to reapply and wait for the visa result. As soon as her visa was rejected, she felt more motivated to go back to Germany and to be a part of this culture. Therefore, she started to prepare for Testdaf exam again for at least 7 hours a day. If she could pass Testdaf exam, she would be able to receive the visa, which would enable her to regain integrativeness. The fear of remaining excluded from the target culture motivated her to focus on German more.

\subsubsection{Instrumentality}

The participant noted that learning German was initially instrumental for her to study architecture in Germany. She emphasized the dichotomy between instrumentality and integrativeness. The instrumentality and integrativeness were often transforming into each other. When both merged, she had more sustained motivation. However, she stated in the interview that for some time German was instrumental for her because as long as she could not pass Testdaf exam, integrativeness would not be operational, functional and pragmatic for her. Therefore, Nil hoped to overcome this instrumental problem as soon as possible. Her ideal situation was that she would be developing her German in Germany for culture per se. However, the longer this instrumental goal lasted, the more chaotic motivational experience she underwent. She was aware that Testdaf exam was reliable, and preparing for it was teaching her a lot. This instrumentality had a sound ground and reliability for her. In one of the excerpts she said as follows:

I have been studying German for almost more than three years and know that Testdaf really measures learners' level. If I pass this exam, I can partially say that I am good at German and gain considerable confidence. However, if this process is lengthened, I may quit taking the exam again. My main concern is not exam but if I fail this exam, I may lose the chance to live in Germany and my whole motivation for this language may fade away, although I do not want this motivation to vanish. However, to what extent is it possible to sustain this motivation in Turkey without going to Germany and being a part of that culture? This is my only concern.

These explanations show that her ideal-self conflicts with her present-self since her future self aims at integrativeness. However, her present situation entails instrumentality. Therefore, her conception of motivation is mixed and shows variation from time to time. Nil does not have a stable focus on the exam or integrativeness. One of these two components may remain dominant depending on time, her interaction with other, the exam results and her psychological state. 


\subsection{Vitality of the L2 Community}

She thought that the German language along with English and French were among the most important languages in Europe. She thought that learning German would privilege her in Europe and Germany, although Turkish, her mother tongue, was important in the target culture. However, the German culture was more important to her than the importance of German both in Germany and Europe. Nil thinks that German language has an important role in Germany and Europe, although it is not widely spoken across the world. Henceforth, it can be said that Nil believes that German language keeps its historical merit and importance.

\subsection{Attitudes toward the L2 Speakers/Community}

The participant had neutral attitude towards the target language in her hometown, Turkey. However, as soon as she started to live in Germany, she improved a positive attitude towards L2 culture and speakers since she witnessed gentle and helpful people that facilitated her life. Her frequent visits to church and cafes in Germany evoked a great interest in German culture. She decided to make some German friends, and therefore decided to live with a German family to gain more daily experiences with them even if she risked the possibility of not understanding their German. In an interview Nil said as follows:

At the beginning I thought that I would not be able to adapt myself to this culture because of some bias against German culture that they were strict. However, whenever I was in a hard situation in this country, they did their best to help me and tried to simplify their German so that I could understand them. When I broke my wrist in Germany, the doctors and nurses treated me so kindly that I was able to understand them. These people were really great. They were really kind and gentle. I wanted to live longer here. However, I had to go back to Turkey owing to my illness. Still, I thought to myself that I would come back to this country soon or late.

These views indicate that Nil developed a positive attitude toward the target culture in time since she had positive experiences that enabled her to overcome her bias problem against the target culture. Even though Nil alone underwent a wrist surgery without her family's or friends' presence, she was able to surmount this problem due to her positive experience and interaction with the target culture and L2 speakers.

\subsection{Cultural Interest}

Nil in both foreign and second language settings showed a great interest in German culture, which motivated her to read German literature and newspapers, listen to radio in L2 and watch German movies. She said that she read 25 stories in German and would follow mainstream German newspapers and radio every day. She also watched German movies criticizing the Second World War and Hitler. She developed a keen interest in German history. Therefore, any movie about German history evoked considerable interest in her. She stated that she could not sustain her interest in German culture for a few months due to the adverse effect of social milieu. Therefore, it can be interpreted that Nil's cultural interest in the target language was immense and relatively constant.

\subsection{Linguistic Self-Confidence}

One of the most important difficulties that she encountered while learning German was that she underwent hard time to develop linguistic self-confidence. She stated that she had high social anxiety and lacked self-confidence while listening to L2 speakers or speaking the target language. One excerpt in the diary was as follows:

I have been trying to avoid speaking to L2 speakers on the grounds that I may not understand them or they may not understand me. I have not been able to overcome this problem for three years. I cannot feel self-confident. I can read, write, speak to myself, and watch online videos. However, my anxiety has been killing me. In Germany, I once felt very confident owing to my German LGBT friends' kind attitudes towards me. They helped me feel relaxed and tried to speak so understandably that I wanted to speak to them for hours because I really could understand them. There is no other experience in my language learning journey that made me feel so comfortable. I am not blaming others. It is not their fault. It is my own problem. Social anxiety is really my own problem because this is the first time I am learning a new language and living in another country. However, my German friends did not threaten me at all. I wanted all German people to treat and look at me like my German LGBT friends. I always fear being judged by others. Even a look may prevent me from speaking or listening to someone to understand. I do not know how I can solve this problem. This trouble may take months or years. However, if I really believe that I have developed my German at an advanced level, then I can feel more comfortable and self-confident to speak or listen.

These ideas show that Nil has been undergoing hard times trying to develop linguistic self-confidence. She diagnoses her own problem by saying that she has social anxiety and fear of being judged. Linguistic self-confidence was positive only in one setting where she spoke German with her close friends. Albeit these 
difficulties, Nil believes that she may be able to cope with this problem when she has an advanced German in four skills.

\subsection{Milieu}

This dimension in her motivation was a serious obstacle because she was extremely adversely affected by the social environment around her. Her family, friends and relatives seldom supported her to study German because studying German in Germany was meaningless to them since this process could take long time. She could not study German in her hometown for a year at all due to the negative effect of the social environment. Her motivation level was reduced to almost zero level. She stated that the support of her social environment faded away in time because she could not pass Testdaf within three years and still could not start the department. She made the following remarks:

Although I wanted to make my dream, studying architecture in Germany and having advanced German, happen in my lifetime, my social environment never believed me that I would succeed. I wasted my whole year in Turkey after spending one year in Germany because the immediate environment around me profoundly affected me and I got totally lost until I received my rejected visa. Then, I came to the realization that I should study again and rise to my feet to study in Germany. I returned to my intensive studies. This social milieu could be my Turkish or German friends, relatives, cousins, family members, teachers, my classmates or even a stranger on my way or on the bus. In Turkey my social environment's negative comments on me significantly decreased my motivation level. This negative effect lasted almost a year. I struggled a lot. Finally, I decided to change my city and set out to live in another city where people would not judge me or make negative comments. I could cope with other problems while learning German. However, these external factors undermined studies more than I expected because I resigned from an important post to start German and study architecture in Germany. This is was a great risk for me. Look at me now. I have been struggling for three years. I lost one year owing to the adverse effect of my social milieu. This was my weakness. I cannot blame them.

The participant made similar remarks in the personal interviews as well and stressed that the social milieu was one of the most important determinants in her life. She stated that she lived in a collectivistic mindset and was trying to transform this mindset into an individualistic mindset. She was trying to make a radical macro change in her life. Therefore, she was always in conflict with her milieu and herself. It can be said that social milieu was one of the most critical determinants in her life. Since her personality was fragile and frail from a social perspective, milieu played the most important role in her motivation.

\section{Limitations and Implications}

The study used only two instruments, diary and interview, to collect data. In addition, only one participant was observed, and therefore the findings cannot be generalized. In addition, only seven dimensions of motivation developed by Dörnyei and Csizér (2002) were taken into consideration. Further studies may include more participants and use nomothetic tools to obtain more generalizable data. Besides, other models or theoretical concepts related to motivation can be used in future research.

\section{Discussion and Conclusion}

This study intended to investigate the motivational dynamics of a second and foreign language learner studying German for three years. The results of the study showed that the dimensions that affected the participants' motivation level most were linguistic self-confidence and milieu. The former refers to an individual problem whose origin derives from the collectivistic family type, while the latter was found to be more determining in that social milieu substantially reduced her motivation. The participant's motivation showed a complex dynamic trajectory due to the mixture of individual aims and a strong sense of social belonging. Similarly, Sade (2011) states that values and expectations prescribed by a given society engender destabilization in individuals. The participant noted that she could not resist social-discursive attractors (Sade, 2011) and that she could not cope with the adverse effects of social milieu (Wenger, 2000). This finding shows that a foreign language learner may not be an independent individual trying to reach a certain goal with constantly sustained motivation. The participant of the study was not explicitly motivated by any teacher but was implicitly motivated. What was more striking was that she could not express her lack of motivation with anyone explicitly. She internalized this problem and experienced the motivation problem in her inner world in a chaotic manner (Larsen-Freeman, 2008).

Similarly, Dörnyei (1998) maintains that motivation inherently contains a multilayered problem rather than a simple explanation. In accordance with Gardner's study (1985), three crucial components of motivation are critical in heightening an individual's desire to learn the target language. First, if intensity of motivation is 
provided, then it is possible that a positive attitude towards the target language may emerge. Therefore, desire to learn, intensity of motivation and attitude seem to be considered three main elements to comprehend motivation (Gardner, 1985). The participant in this study also intrinsically had the desire and intense motivation to learn German. However, external factors often hindered her from focusing on the target language. When the internal and external factors were positively combined for the participant, she had sustained motivation for a while. However, the negative effect of social milieu on her influenced her inner motivation. It was also found that even in a 45-minute lesson, motivation variability might be observed depending on types of topics taught in classroom settings and that there seem interrelated factors that explain individual and motivation variability composed of multi-layered issues (Waninge, Dörnyei, \& De Bot, 2014). Motivation in a larger context such as target language country can be influenced by change, stability and context, three of which mainly constitute Complex Dynamic Systems (Larsen-Freeman \& Cameron, 2008; Waninge, Dörnyei, \& De Bot, 2014). Based on these findings, it can be interpreted that the participant showed various reactions to the issue of motivation because her context and stability showed constant changes. Thus, it can be said that motivation system is not static but quite dynamic. Besides, Csizér and Dörnyei (2005) found that integrativeness is one of the most effective and important factors that affect motivation quite considerably. However, in this present study it was pointed out that the participant's social milieu and linguistic self-confidence were more significant factors that influenced the participant's motivation, although she had a positive attitude towards the target culture.

It can be concluded from the findings that fostering learners' linguistic self-confidence and social milieu could endorse their motivation level (Dörnyei \& Kubanyiova, 2014). Creating mere positive attitudes towards and interest in target language culture, community and speakers might be insufficient to augment motivation in classroom environments. Therefore, external factors should also be taken into consideration by practitioners. It could be interpreted that there always exist external risks outside classroom setting that might affect learners' motivation and even determine their social identity in class. Talking about learners' external factors may boost their motivation level. Teachers should make learners feel that teachers are aware of these external factors. Thus, it can be said that lessening the problem of social pressure taking place outside the class may help learners gain linguistic self-confidence (Dörnyei, 2013). Since motivation is a multi-layered problem, it is important to take seven dimensions of motivation developed by Dörnyei and Csizér (2002).

One of the neglected dimensions of motivation in classroom environment is milieu that needs to be considered. Milieu suggests that learners are exposed to outsiders' impact (Ryan \& Deci, 2000). Therefore, additional sessions should be applied in classrooms so that the nature of motivation problem can be comprehended. Dynamic nature of motivation often hardens teachers' job and causes teachers to make complaints about learners' low motivation since teachers step into classes expecting them to always have heightened and sustained motivation which cannot be easily provided without applying some useful strategies developed by Dörnyei and Kubanyiova (2014). The participant's diary related to motivation suggests that motivation is highly chaotic and dynamic. Based on these findings, it can be stated that once a learner believes that high motivation has been provided, a sudden external factor may diminish motivation level (Larsen-Freeman, 2008). The participant in this present study also noted that living in the target culture helped her to be exempt from social milieu in her native country owing to the nature of collectivist cultural values. This axiomatic nature of collectivist culture should be reassessed in EFL classes and investigated. Questioning these external factors experienced outside classes and implementing critical thinking tasks in classes to heighten motivation level can produce a new perspective in learners because learners can be aware that teachers handle motivation problem from a different angle. Teachers should realize that motivation problem is not a mechanical or physical issue that can be surmounted through superficial explanations (Dörnyei, 2013; Dörnyei \& Ryan, 2015).

Striving to comply with the goals of the curriculum may victimize learners since few curricula take motivation problem into consideration. While curriculum designers are preparing the curriculum, there is little or no room for the dynamic and chaotic nature of motivation. Learning is considered linear and mechanical. As for learners, they are still perceived as individuals who have to fulfill tasks written in course books or assigned by teachers regardless of their motivational background (Thornbury, 2013). Since there is a course that agents (teachers and students) have to reach in accordance with a curriculum, the importance of motivation is naturally degraded and ignored because any activity to spend time on motivation is perceived as a waste of time. The mounting evidence indicates that motivation has a dynamic, chaotic and complex nature. Therefore, teachers should handle this problem with care by scaffolding their learners. Lack of motivation may directly affect learners' identity and autonomy and is not only a problem of motivation that can be mechanically tackled since high motivation may enhance learning curve significantly. Therefore, various theoretical perspectives developed in recent decades can be applied in analysis and understanding of motivation. 


\section{References}

Bandura, A. (1997). Self-efficacy: The exercise of control. New York: Worth Publishers.

Boo, Z., Dörnyei, Z., \& Ryan, S. (2015). L2 motivation research 2005-2014: Understanding a publication surge and a changing landscape. System, 55, 145-157. https://doi.org/10.1016/j.system.2015.10.006

Bowden, J., Dall'Alba, G., Martin, E., Laurillard, D., Marton, F., Masters, G., \& Walsh, E. (1992). Displacement, velocity, and frames of reference: Phenomenographic studies of students' understanding and some implications for teaching and assessment. American Journal of Physics, 60(3), 262-269. https://doi.org/10.1119/1.16907

Cooke, N. J. (1994). Varieties of knowledge elicitation techniques. International Journal of Human-Computer Studies, 41(6), 801-849. https://doi.org/10.1006/ijhc.1994.1083

Csizér, K., \& Dörnyei, Z. (2005). The internal structure of language learning motivation and its relationship with language choice and learning effort. The modern Language Journal, 89(1), 19-36. https://doi.org/10.1111/j.0026-7902.2005.00263.x

Deci, E. L., \& Ryan, R. M. (1985). Intrinsic motivation and self-determination in human behavior. New York: Plenum. https://doi.org/10.1007/978-1-4899-2271-7

Dörnyei, Z. (1998). Motivation in second and foreign language learning. Language Teaching, 31(3), $117-135$. https://doi.org/10.1017/S026144480001315X

Dörnyei, Z. (2002). The motivational basis of language learning tasks. In Z. Dörnyei, \& P. Skehan (Eds.), Individual differences in second language acquisition (pp. 137-158). Amsterdam: John Benjamins. https://doi.org/10.1075/11lt.2.10dor

Dörnyei, Z. (2009). The L2 motivational self-system. In Z. Dörnyei, \& E. Ushioda (Eds.), Motivation, language identity and the L2 self (pp. 9-42). UK: Clevedon.

Dörnyei, Z. (2013). Motivational strategies in the language classroom. Cambridge: Cambridge University Press.

Dörnyei, Z., \& Csizér, K. (2002). Some dynamics of language attitudes and motivation: Results of a longitudinal nationwide survey. Applied Linguistics, 23(4), 421-462. https://doi.org/10.1093/applin/23.4.421

Dörnyei, Z., \& Kubanyiova, M. (2014). Motivating learners, motivating teachers: Building vision in the language classroom. Cambridge: Cambridge University Press.

Dörnyei, Z., \& Ryan, S. (2015). The psychology of the language learner revisited. New York: Routledge.

Dörnyei, Z., MacIntyre, P. D., \& Henry, A. (Eds.). (2014). Motivational dynamics in language learning. Bristol, UK: Multilingual Matters.

Gardner, R. (1985). Social psychology and second language learning: The role of attitudes and motivation. London: Edward Arnold.

Larsen-Freeman, D. (1997). Chaos/complexity science and second language acquisition. Applied Linguistics, 18(2), 141-165. https://doi.org/10.1093/applin/18.2.141

Larsen-Freeman, D. (2012). Complex, dynamic systems: A new transdisciplinary theme for applied linguistics? Language Teaching, 45(2), 202-214. https://doi.org/10.1017/S0261444811000061

Larsen-Freeman, D., \& Cameron, L. (2008). Complex systems and applied linguistics. Oxford: Oxford University Press.

MacIntyre, P. D., Dörnyei, Z., Cl_ement, R., \& Noels, K. A. (1998). Conceptualizing willingness to communicate in a L2: A situational model of L2 confidence and affiliation. The Modern Language Journal, 82(4), 545-562. https://doi.org/10.1111/j.1540-4781.1998.tb05543.x

Marton, F. (1981). Phenomenography: Describing Conceptions of the World Around Us. Instructional Science, 10, 177-200. https://doi.org/10.1007/BF00132516

Marton, F., \& Booth, S. (1997). The idea of phenomenography. In F. Marton, \& S. Booth (Eds.), Learning and Awareness (pp. 110-136). Mahwah, New Jersey, USA: Lawrence Erlbaum Ass.

Mason, J. (2002). Qualitative researching. Thousand Oaks, CA.: Sage Publications.

Ryan, R. M., \& Deci, E. L. (2000). Intrinsic and extrinsic motivations: Classic definitions and new directions. Contemporary Educational Psychology, 25(1), 54-67. https://doi.org/10.1006/ceps.1999.1020 
Sade, L. A. (2011). Emerging selves, language learning and motivation through the lens of chaos. In G. Murray, X. Gao, \& T. Lamb (Eds.), Identity, motivation and autonomy in language learning (pp. 41-56). Bristol: Multilingual Matters.

Thornbury, S. (2013). Resisting coursebooks. In J. Gray (Ed.), Critical perspectives on language teaching materials (pp. 204-223). London: Palgrave Macmillan. https://doi.org/10.1057/9781137384263_10

Waninge, F., Dörnyei, Z., \& De Bot, K. (2014). Motivational dynamics in language learning: Change, stability, and context. The Modern Language Journal, 98(3), 704-723. https://doi.org/10.1111/modl.12118

Weiner, B. (2010). The development of an attribution-based theory of motivation: A history of ideas. Educational Psychologist, 45(1), 28-36. https://doi.org/10.1080/00461520903433596

Wengraf, T. (2001). Qualitative Research Interviewing: Biographic Narratives and Semi-Structured Methods. Thousand Oaks, CA, London and New Delhi: Sage. https://doi.org/10.4135/9781849209717

\section{Copyrights}

Copyright for this article is retained by the author(s), with first publication rights granted to the journal.

This is an open-access article distributed under the terms and conditions of the Creative Commons Attribution license (http://creativecommons.org/licenses/by/4.0/). 